\title{
Solidariedade intergeracional: perspectivas e representações
}

\author{
Intergenerational solidarity: perspectives and representations
}

\author{
Maria da Luz Leite Cabral, ${ }^{1}$ Regiane da Silva Macuch² \\ 'Escola Superior de Saúde do Alcoitão, Alcabideche, Cascais, Portugal. \\ 2Centro Universitário de Maringá (UniCesumar), Maringá, PR, Brasil.
}

Recebido em: 29/08/2016 / Aceito em: 27/09/2016 / Publicado em: 18/10/2016

maria.cabral@essa.pt

\section{RESUMO}

As mudanças demográficas, o envelhecimento populacional e a complexidade dos fenômenos sociais na contemporaneidade anunciam o distanciamento entre diferentes grupos etários. Objetivo: descristalizar preconceitos face à idade (idadismo) na sensibilização de maior solidariedade e convivências/interações entre gerações. Método: no percurso da intervenção comunitária, para entender o impacto de um Encontro no âmbito do Ano Europeu do Envelhecimento Ativo e Solidariedade entre Gerações (AEEASE), validado a partir de quatro grupos (2 grupos de idosas e 2 grupos de jovens) num total de 100 intervenientes. A amostra foi constituída por dois grupos de 25 pessoas idosas; um que participou no encontro e outro que não participou e outros dois grupos de 25 jovens distribuídos de igual modo; todos da região do Porto, Portugal. Neste artigo, pretende-se refletir sobre a pertinência destes encontros na promoção da educação intergeracional impulsionadora de solidariedades e cidadania participativa. Partiu-se da aplicação de um questionário aos participantes e não participantes do Encontro. Resultados: os dados sugerem menor concordância no item do suicídio entre aqueles que participaram no encontro e proporcionalmente níveis mais elevados de concordância no item do idadismo. É de salientar o item do preconceito, em relação aos jovens, expresso no grupo das pessoas idosas, entusiasmado pela forma eloquente como a Coordenadora do encontro AEEASE falou a favor das pessoas idosas. Considerações finais: em suma, particularmente para as pessoas idosas, esta intervenção terá de ser alargada e sustentada no tempo e baseada no diálogo simétrico, para contribuir na desconstrução de estereótipos em relação aos jovens.
Palavras-chave: Solidariedade; Educação Intergeracional; Preconceito e Idadismo.

\section{ABSTRACT}

Demographic changes, population aging and the complexity of social phenomena in contemporary announce the gap between different age groups. Objective: disincorporate prejudices against age (ageism) in awareness of greater solidarity and conviviality / interactions between generations. Method: in the course of community action to understand the impact of a meeting in the European Year of Active Ageing and Solidarity between Generations (EYAASBG), validated from four groups (2 elderly groups and two youth groups) in total 100 players. The sample consisted of two groups of 25 elderly, who attended the meeting and another who did not participate, and two groups of 25 young people equally distributed, all in the region of Porto, Portugal. This article aims to reflect on the relevance of these meetings in promoting intergenerational driving education solidarities and participatory citizenship. It started from the application of a questionnaire to participants and non-participants of the meeting. Results: the data suggest less agreement on the suicide item among those who attended the meeting and proportionately higher levels of agreement on ageism item. It should be noted the prejudice of the item in relation to young people, expressed in the group of elderly, excited by the eloquent way the meeting Coordinator EYAASBG spoke in favor of the elderly. Concluding remarks: in short, particularly for the elderly, this intervention will have to be extended and sustained in time and based on symmetrical dialogue, to contribute to the deconstruction of 
stereotypes about young people.

Keywords: Solidarity; Intergenerational Education, Prejudice and Ageism.

\section{INTRODUÇÃO}

As mudanças populacionais, o aumento da longevidade e a diminuição da natalidade originam o enveIhecimento da população e um maior distanciamento das trocas relacionais entre gerações. Os projetos de intervenção comunitária promotores de envelhecimento ativo e da solidariedade intergeracional revestem-se, por isso, de um interesse crescente. ${ }^{1}$ Neste sentido, este estudo considera as suas aplicações na educação intergeracional, centralizada no desenvolvimento/partilha de saberes, atitudes e competências que proporcionam a interação e solidariedade intergeracionais. Desta forma, sustentamos a validade da intervenção socioeducativa que envolve dois grupos etários extremados, pessoas idosas institucionalizadas e jovens estudantes do ensino profissionalizante da região do Porto.

O motivo, subjacente a este estudo, reside no fato de entendermos quais são, habitualmente, os grupos em que as perspectivas e representações do preconceito, face à idade e face à solidariedade intergeracional, têm sofrido grande transformação ao longo do tempo. Não só por força das políticas sociais e educacionais praticadas, tendencialmente insuficientes e/ou inoperacionais, cada vez mais desarticuladas da sociedade, mas também por força da própria alteração profunda do tecido societal, que confere progressiva complexidade aos fenômenos sociais. A individualização, ${ }^{2}$ porquanto de "expressão neoliberal», isola as pessoas destas faixas etárias, ao não promover situações ou oportunidades de interações/convivências e de solidariedades. A intervenção patenteada pelas instâncias responsáveis, provenientes de políticas sociais e educacionais, é tantas vezes orientada para dar resposta a situações concretas de ruptura, em que a situação de risco é iminente e/ou a retaguarda familiar nula ou inexistente. As lógicas do mercado de consumo da "sociedade individualizada" provocam, por conseguinte, algumas demandas na população e, acreditamos, em particular nos dois grupos alvo do nosso foco de interesse: os jovens e as pessoas idosas. ${ }^{2}$

A construção social a que estão sujeitos origina a perspectiva da diferença associada ao estatuto social, evidenciado e vivenciado, em função da faixa etária e/ ou pela representação social em sociedade, das pessoas de idade mais avançada e dos jovens. ${ }^{3}$ Além disso, permite-nos demonstrar o argumento supra referenciado, de que não obstante o discurso de conflitos geracionais, em particular num contexto socioeconômico, onde a disputa por recursos escassos está fenomenizada e comprometida, as lógicas políticas e as demandas governamentais promovem ou deveriam promover diferentes discursos sobre o ser-se Jovem ou Idoso na contemporaneidade. Sendo Portugal, um dos países da União Europeia com grande índice de envelhecimento, o incremento da população envelhecida origina desafios e exigências de várias ordens na sociedade atual. Estima-se que em 2050 será um dos países mais velhos do mundo. ${ }^{4}$

Para além disso, no contexto da crise econômica atual em que frequentemente a informação da comunicação social e/ou opinião pública, sobre políticas e recursos públicos, a distribuição de riqueza, de bens e de serviços sugere muitas vezes o "despesismo" decorrente desta alteração demográfica e impulsionando a competição entre gerações. ${ }^{5}$

A ambição de garantir melhores condições e consequentemente melhor qualidade de vida a estes grupos etários, particularmente vulneráveis à pobreza, é muitas vezes determinada em função do número de pessoas ativas e de lógicas economicistas. Desta forma, a intervenção comunitária, no domínio da educação intergeracional poderá contribuir para combater preconceitos e cristalizações e potenciar/promover políticas de solidariedade intergeracional. Assim, o objetivo do estudo é descristalizar preconceitos face à idade (idadismo) na sensibilização de maior solidariedade e convivências/ interações entre gerações.

\section{Revisão da literatura/modelos}

A teoria da solidariedade intergeracional foi desenvolvida por Bengtson e colegas, ${ }^{6}$ focalizando-se nas relações entre filhos adultos e pais, sobretudo pessoas idosas. A solidariedade intergeracional não é, contudo, linear ou livre de tensões ou ambiguidades, motivada fundamentalmente por sentimentos partilhados a este respeito:

The theoretical debate on the concept of intergenerational solidarity is centered on the too normative and too harmonious view on parent-child relations. The criticism is directed towards the conceptualization of intergenerational relations. The argument is that dimensions of solidarity cannot disclose a simultaneous occurrence of positive and negative feelings. ${ }^{7}$

As relações intergeracionais são, assim, compreendidas em diferentes perspectivas, uma vez que prestam atenção ao mapeamento das dimensões na sociedade e sua conflitualidade. A Solidariedade Intergeracional familiar é uma construção multifacetada e multidimensional que se refere a seis dimensões de interação pai-filho ${ }^{6}$ e que se abordam em seguida.

Quando falamos de solidariedade estrutural reportamo-nos à estrutura de oportunidades de estabelecimento de relações intergeracionais, bem como à proximidade geográfica dos membros da família. A solidariedade associativa constitui a frequência e os padrões de interação em vários tipos de atividades nas quais os membros da família se envolvem. A solidariedade afetiva representa o tipo e o grau de sentimentos positivos mantidos entre os membros da família, assim como o grau de reciprocidade desses sentimentos. No caso da solidariedade normativa, esta pode ser vista como a força de compromisso para executar as funções familiares e satisfazer as obrigações familiares. A solidariedade consensual é o grau de acordo sobre valores, atitudes e crenças entre os membros da família. Por fim, a solidariedade funcional é o grau de apoio e troca de recursos entre os membros da família. Em inúmeras publicações Bengtson e o seu grupo de pesquisa forneceram evidências empíricas, quanto à relevância das diferentes dimensões da solidariedade intergeracional. 
O diálogo e a solidariedade geracional têm padrões diferenciados em diversos contextos e grupos sociais distintos, dada a própria complexidade das relações intergeracionais, que advém das transformações da e na sociedade. Na senda deste tema, há que referir que a solidariedade intergeracional de Bengtson e colaboradores é uma construção, que muitas vezes escamoteia a diversidade de experiências. Da mesma forma, a solidariedade intergeracional é tradicionalmente operacionalizada uniformizando a diversidade da experiência familiar. Assim, ela não leva em consideração o modo como certos grupos de pessoas são muitas vezes privilegiados em detrimento de outros. ${ }^{8}$

$\mathrm{O}$ aumento crescente da longevidade tem repercussões não só nas novas gerações, reflexo do tempo de vida de cada um, como no aumento das pessoas que atingem idade avançada. A solidariedade intergeracional ultrapassa por isso, em muito, o contexto familiar, e esta realidade torna complexa a rede de relações familiares, mas também sociais, na medida em que cresce a necessidade de solidariedade e cooperação social. Parece-nos importante salientar que, uma sociedade de e para todas as idades pressupõe uma outra (com)vivência entre gerações e, claro, uma interação saudável entre idades. A maior longevidade humana constitui, já o dissemos, um desafio crescente à sociedade atual. ${ }^{9}$

Ao estimular as potencialidades das pessoas idosas, sustenta-se a continuidade do respectivo contributo para o desenvolvimento da comunidade/sociedade: neste sentido, a mudança está na própria família por meio da educação e da sensibilização para a importância de se discutir o relacionamento entre jovens e velhos. ${ }^{9}$

Segundo Durkheim, tanto uma organização como uma sociedade só afirmam a sua realidade unitária e a sua existência na medida em que são assimiladas a uma divindade transcendental de ordem não humana, ou extra-humana, negando o seu caráter contingente, precário, compósito e evolutivo. Esta realidade bem entendida é apenas ilusória, tal como a unidade de grupo ou de uma organização. Uma outra forma de descrever a realidade organizacional, segundo Lévy, é defini-la como "tecido discursivo", cuja trama (as regras) constitui a ordem simbólica, a história, e cujo fio (as representações, o sentido) constitui a ordem imaginária. Desta forma, torna-se claro que as exigências da sociedade no tecido familiar ocasionem alterações significativas nas vivências/convivências da solidariedade intergeracional: - os jovens, como afirmam Coimbra, Ribeiro \& Fontaine, ${ }^{8}$ - são, provavelmente, o melhor exemplo de como as mudanças na industrialização, a emancipação e a secularização da Europa Ocidental influenciam atitudes e comportamentos pessoais, aumentando a autonomia e individualismo. ${ }^{8}$ Este modo de agir fomenta que, na atualidade, os jovens e as pessoas idosas não convivam, ora por conta da deslocalização, ora pela precariedade dos empregos, ocasionando a fragilidade das responsabilidades das famílias face às exigências da sociedade e das políticas sociais que pouco ou nada fazem para contrariar a tendência dos percursos de vida cada vez mais difíceis e solitários.

A articulação entre contextos sociais de vivência dos jovens e das pessoas idosas, bem como as políticas difundidas e operacionalizadas na manutenção e construção da sua identidade e da participação cívica, não promovem, de uma forma geral, a convivência entre gerações. Ao contrário, a lógica econômico-produtiva põe em causa os objetivos enunciados nas políticas sociais e as responsabilidades reiteradas às famílias, dificultando a solidariedade intergeracional. Por isso, no contexto atual, refletir acerca de solidariedade intergeracional implica refletir acerca da cidadania e da participação. Igualmente, não podemos falar de cidadania sem falarmos de cidadãos/ãs e ser cidadão/ã, uma vez que, de acordo com Perrenoud, citando Le Robert é a qualidade de cidadão que está em causa. No entanto, ser cidadã(o) é um conceito que, ao longo dos tempos, se foi alterando: se na antiguidade ser cidadão era pertencer a uma nação, com a revolução francesa este conceito sofreu alteração e passou a ser - outorgada automaticamente na idade da maioridade civil. Deste modo, a cidadania, segundo este autor, é permanentemente produzida e habitada por uma conjuntura própria. Os direitos e os deveres resultantes da condição de cidadão/ã consideram-se unidos pelo vínculo a uma comunidade particular. ${ }^{10}$ Para T.J. Marshall a cidadania é (...) um status concedido aqueles que são membros integrais de uma comunidade. Todos aqueles que possuem o status são iguais com respeito aos direitos e obrigações pertinentes ao status (...). no qual todos (...) são iguais com respeito aos direitos e obrigações. ${ }^{11}$ No entanto, podemos considerar esta definição vaga, porque se refletirmos sobre o que é ser membro integral de uma comunidade, verificamos que varia de acordo com os valores dominantes de um determinado contexto.

Nas sociedades ocidentais e de um modo geral, podemos considerar que a cidadania é vista, pelo menos teoricamente, como um status universal e tem em conta três tipos de direitos - civis, políticos e sociais - bem como os deveres a eles associados. A educação, enquanto direito social de todos os cidadãos, é fundamental para a tomada de consciência dos seus direitos civis, do exercício dos seus direitos políticos e da reivindicação dos seus direitos sociais. Os direitos sociais são os mais relevantes no nosso estudo, pois referem-se ao direito mínimo de bem-estar econômico e à segurança, ao direito de participar nas mais variadas interações sociais e educativas promotoras de cidadania. Assim, ao aludir às questões resultantes do estatuto social das pessoas idosas na sociedade, intimamente ligadas à solidariedade intergeracional, há que distinguir entre cidadania atribuída e cidadania reclamada que surgem pelos processos de globalização e necessidade de se reestruturar os processos identitários dos sujeitos. ${ }^{3} \mathrm{Na}$ pós-modernidade, ${ }^{2}$ passamos de uma cidadania atribuída outorgada pelo Estado-Nação, para uma cidadania reclamada fundada por diferentes grupos sociais, entre eles o grupo das pessoas idosas e dos jovens. Na cidadania atribuída, o que estava em jogo era a igualdade política, social e cultural, enquanto que na cidadania reclamada, o que está em causa é o direito do sujeito à diferença, o direito a ter voz, o direito à pluralidade. Tal como Marshall11 também Stoer e Magalhães, ${ }^{3}$ consideram que o trabalho da escola/educação é fundamental para o desenvolvimento e reconhecimento da cidadania e da participação.

A pós-modernidade veio trazer um nova perspec- 
tiva, uma nova ontologia social e, com ela, surgiram mudanças no modo como as relações sociais entre os grupos e os indivíduos eram legitimadas. Ao contrário da modernidade, o corpo social não é homogêneo e, como tal, os projetos de cidadania terão que ser repensados, tendo em conta a identidade e o sentimento de pertencer ao grupo. ${ }^{2}$

Deste modo, expressões como velhice e velho, ao refletirem um significado pejorativo, foram substituídas por Terceira Idade e Idosos, para não ofender o pudor social. Estas são expressões anacrônicas que não existem por si mesmas e, sendo construções sociais, são igualmente portadoras de uma cultura. Neste sentido, o que existe é o ser humano pleno a caminho de sua autorrealização, como pessoa humana, como indivíduo inimitavelmente único e como cidadão/ã. Neste sentido, a definição de velhice segundo Karsz ${ }^{12}$ alude à representação ideológica sob a qual as pessoas cronologicamente idosas são reconhecidas enquanto ilustrações animadas da velhice e por outro lado desconhecidas enquanto sujeitos de desejos inscritos em classes sociais ${ }^{12}$

Esta construção social do que significa ser velho alterou-se, ao longo dos tempos, no seu significado, valor e função social. Ela pode ser definida de acordo com os novos conceitos/definições de idade, portanto a velhice invisível, inerente às Sociedades Tradicionais Ocidentais em que a condição de ser velho estava associada à função patrimonial (séc. XIX e início do séc. $X X$ ), a solidariedade para com os idosos era familiar, privada e realizada no espaço doméstico. O espaço público (instituições e lares) destinava-se à velhice desprotegida. $O$ envelhecer não era condição para aquisição de um novo estatuto social. A esta segue-se a velhice visível, inscrita nas Sociedades Industriais e pós Industriais, fruto de um modelo forte de estratificação, segregação etária, de acordo com o ciclo produtivo e na construção social do grupo de idosos associada à reforma. A velhice visível, como refere Giddens ${ }^{13}$ é uma das "consequências da Modernidade», resultante das transformações que ocorreram nas sociedades industrializadas. Estas condições determinam que socialmente se começasse a equacionar a velhice como uma situação problemática a necessitar de resolução coletiva. A velhice, enquanto fenômeno social, é um produto da construção social resultante do confronto de ideias e de interesses entre grupos sociais e entre gerações de modo a obter poder de manipulação sobre as classes de idades. ${ }^{13}$ Apesar de ao longo da história da humanidade muito se tenha falado sobre a idade, o preconceito associado à idade é uma realidade, e o idadismo ganha nova importância na sociedade atual. Em consideração, Neto, ${ }^{14}$ adverte que os estereótipos etários são sistemas de crenças que se atribuem a membros de grupos de diferentes idades, simplesmente pelo facto de pertença a esses grupos. ${ }^{14}$ Atualmente, o preconceito face à idade manifesta-se individualmente e institucionalmente, pelo que urge a definição de um plano de ação com abrangência e eficácia. A alteração demográfica ocasionou mudança na solidariedade e na interdependência das gerações e classes que, de algum modo, estavam na base de funcionamento do Estado, colocando em causa os mecanismos de financiamento e de sobrevivência do Estado Providência.
Portanto, a política social ao procurar atenuar as desigualdades sociais, principalmente, nos grupos de maior vulnerabilidade, neste contexto de crise econômica evidencia os grupos de fragilidade relacional traduzida na escassez de laços e de contatos. O grupo de idosos é, neste sentido, um grupo dos constantemente excluídos, ora do mundo de trabalho pela sua idade (consequentemente de menor importância social), ora pela falta de poder de consumo (baixos rendimentos, baixo consumo). Os idosos são também muitas vezes excluídos da própria família, que lhe providencia uma retaguarda fragilizada e/ou mesmo nula. Esta debilidade é fomentada pela economia de mercado desregulada e pela inexistência efetiva de um Estado Providência com poder de regular os déficits dos cidadãos/ãs. Este conceito está de tal forma enraizado na nossa sociedade que, por um lado, se teme envelhecer, existindo a obrigação de não parecer velho (para não se tornar incompetente e incapaz aos olhos dos outros) e, por outro, se tratam as pessoas idosas como crianças e associados exclusivamente a papéis sociais de menor relevo. Para além disso, perante a crise económica e a consequente escassez de recursos, aumenta a probabilidade de maior competição do que solidariedade entre gerações. ${ }^{8}$

Portanto, modelos políticos e educativos de assimilação, integração e inclusão refletem concessões sobre a diferença/diversidade que espelham a ideia de que a diferença é pensada não como desvio exótico, mas numa preocupação "exclusivamente ocidental». ${ }^{3}$ Da mesma forma, as políticas sociais no modo como contemporaneamente se configuram na atual sociedade de risco, estão fundadas no princípio da gestão do risco e de responsabilidade individual. ${ }^{15}$ Parece evidente, tal como Beck defende, que não é uma opção que alguém possa escolher ou rejeitar no decurso de disputas políticas. Ocorre na continuidade dos processos de modernização autonomizados, que são cegos e surdos aos seus próprios efeitos e ameaças. (...) Cada vez mais os conflitos sociais não são tratados como problemas de ordem (que por definição são orientados para a clareza e para a capacidade de decisão), mas como problemas de risco. Estes problemas de risco são caracterizados por terem soluções ambíguas (...) face a uma crescente falta de clareza (...). ${ }^{3}$

Torna-se urgente melhor compreender e acionar novos espaços de proximidade e partilha entre gerações, de modo a contrariar a perda de contato evidenciada, baseada em meros relacionamentos superficiais, bem como reconsiderar a aposta numa educação intergeracional, centralizada no desenvolvimento/partilha de saberes, atitudes e competências que proporcionem a interação geracional, no sentido de associar gerações díspares no desenvolvimento de novas relações/ afinidades. Ao facilitar uma melhor compreensão de cada geração, é possível descristalizar e desconstruir alguns dos estereótipos associados à idade, e desta forma construir uma sociedade melhor. Até porque, associados a estes estereótipos, surgem, como causas e consequências, não só as supra enunciadas questões da inclusão e exclusão, mas também as questões da pobreza e desigualdade. Este funcionamento do mundo político (da vida em sociedade) em ligação conjuntural às políticas em vigor, insinua que as regras são nor- 
malmente impostas pelo capital e transformam hábitos, costumes e a cultura dos povos de uma forma global, fenômenos que vão desde a transformação da intimidade à reinvenção das tradições $e$ ao culto do efémero. ${ }^{3}$

\section{MÉTODO}

Este estudo teve como ponto de partida a organização de encontro intergeracional, na Faculdade de Psicologia e de Ciências da Educação da Universidade do Porto, possibilitando a oportunidade de centrar a intervenção/investigação em dois públicos-alvo que permitiam efetivamente cruzar as duas realidades que se pretendia estudar, bem como as implicações da educação intergeracional centralizada no desenvolvimento/ partilha de saberes, atitudes e competências. Organizar, implementar e compreender o impacto do Encontro de intervenção comunitária AEEASE, influente no enveIhecimento ativo e da solidariedade intergeracional, é, assim, o objetivo central do nosso estudo.

A intervenção visou sobretudo questionar, desafiar e confrontar o porquê e o sentido das práticas intergeracionais e, ao mesmo tempo, investir na sua transformação/modificação e melhoria. A avaliação do seu impacto ocorreu por meio da comparação dos estereótipos em relação à faixa etária de jovens e idosos, que participaram e não participaram no encontro intergeracional, procurando entender o discurso sobre a representação do envelhecimento e as várias perspectivas, afim de refletir sobre questões relativas ao envelhecimento, ao preconceito face à idade e as interações/convivências entre gerações. Ao reiterarmos a importância da aprendizagem ao longo da vida, o intercâmbio geracional é um pressuposto estabelecido ao longo da história da humanidade. Por conseguinte, esta troca de saberes, a partilha e a reflexão entre pessoas idosas e jovens permite lançar o debate sobre a temática, visando as preocupações, os desafios e a sensibilização para a pertinência do assunto do envelhecimento ativo na perspectiva demográfica que se vislumbra e a importância da solidariedade intergeracional nas sociedades atuais afim de contrariar o egocentrismo crescente.

No âmbito desta investigação, mais do que agenciar respostas categóricas ou comprovar um conjunto de suposições representadas inicialmente, pretendeu-se levantar questões e enigmas que possam vir a configurar uma problemática sustentada na complexidade dos fenômenos sociais e na reflexão crítica em torno de questões de solidariedade intergeracional, mas, e também, nas inter-relações com a temática da exclusão/ inclusão social. O trabalho de intervenção/investigação desenvolveu-se em torno das representações e perspectivas que, de modo geral, são veiculadas na opinião pública (e na academia) sobre envelhecimento, a carecer posicionamento político. A procura do entendimento da dimensão do impacto, que a construção do envelhecimento e da evolução demográfica, comprovado nas sociedades ocidentais, tem sobre as representações dos jovens em relação às pessoas idosas e vice-versa. Importa compreender a consequência das alterações nos modos de vida, sentidos e significados destes grupos etários; e particularizar a (falta de) convivência e (de) solidariedades intergeracionais e delinear intervenções que contrariem essa consequência. A explanação sobre as consequências, os sentidos e significados destes grupos etários em confronto com uma sociedade cada vez mais individualista. A consequência deste fenômeno social, quer por falta de interações, quer pelo fato de estarem tantas vezes associados/classificados, como socialmente excluídos. Portanto, os marginalizados da e na sociedade atual e de consumo são consequentemente, banidos por força da lógica produtiva do capitalismo. A articulação entre contextos sociais de vivência das pessoas idosas e dos jovens é, por isso, urgente, refletindo simultaneamente acerca das políticas difundidas e operacionalizadas que possam promover a manutenção e construção da sua identidade e a sua participação cívica. Pretende-se, por isso, contrariar, por meio da intervenção comunitária, a lógica econômico-produtiva que põe em causa os objetivos enunciados nas políticas sociais e as responsabilidades reiteradas das famílias que não facilitam ou mesmo dificultam a solidariedade intergeracional.

A aplicação do questionário neste estudo teve como objetivo explorar as representações das relações intergeracionais de jovens e pessoas idosas. Desenvolveu-se por meio de duas estratégias, no grupo dos jovens. O mesmo foi auto administrado coletivamente, isto é, foi entregue no final de uma aula, onde os alunos puderam preencher de forma autônoma.

No caso das pessoas idosas, foi administrado individualmente, sob forma de entrevista, na presença da investigadora e recolha de informação para o estudo, afim de que se pudesse constituir como possibilidade de expressão de expectativas, opiniões e sentimentos que pudessem ser cuidadosamente elaborados. Tanto no caso dos jovens, como no caso das pessoas idosas, a administração do questionário foi antecedida de consentimento informado elaborado e aplicado dentro das normas da Faculdade de Psicologia e de Ciências da Educação da Faculdade do Porto.

As perguntas foram preparadas e codificadas para que os intervenientes, selecionassem obrigatoriamente uma das opções que lhes foram propostas, o que permitiu a conversão em estudos mais consistentes e elaborados. Assim, o inquérito por questionário de administração direta, no caso dos jovens, e de administração indireta, no caso das pessoas idosas, uma vez que foi completado pela investigadora, na sequência das respostas dos grupo estudo, respeitou, todavia, a confidencialidade das respostas.

A aplicação dos questionários, no caso específico das pessoas idosas, permitiu uma interação verbal entre a profissional/investigadora e os intervenientes em posição de face a face, necessária para facilitar a ligação e perspectivar a maneira mais real e mais realista de explorar a relação de comunicação, pois consente aos intervenientes que se expressem de forma livre, e segundo este autor, longe de serem instrumentos nas mãos do pesquisador, eles conduzem de alguma maneira a entrevista e a densidade e a intensidade do seu discurso. ${ }^{16} \mathrm{O}$ período de aplicação dos instrumentos decorreu nos meses de março, abril e maio de 2013, tendo sido administrados 105 questionários, 5 dos quais foram anulados por se encontrarem incompletos. Os principais obstáculos à regência do instrumento 
foram a dificuldade em conciliar com a disponibilidade dos jovens, e a necessidade de acompanhamento no momento da resposta ao instrumento por parte das pessoas idosas, porque achavam as perguntas muito parecidas e em alguns casos incompreensíveis, atingindo por vezes uma duração média de 25 minutos.

O trabalho de intersubjetividade decorrente desta técnica de investigação consiste de acordo com Bourdieu, em acrescentar uma nova perspectiva ao modo como se lê um determinado fenômeno social em contexto; daí a necessidade de um conhecimento prévio, passível de ser reinterpretado pela realidade que é socialmente construída.

A dinâmica da investigação apresenta um plano que se inscreve em misto/específico no âmbito da investigação/ação, onde um conjunto amplo de questões consideradas relevantes para o estudo é analisado e compreendido. Este método visa analisar/compreender o fenômeno social relativo às populações alvo - jovens e pessoas idosas - desta pesquisa, a partir das informações que os/as intervenientes foram facultando. Ainda assim, os inquéritos por questionários podem manifestar alguns limites/problemas, quando aplicados e não tendo em conta rigor na amostra, formulação clara e unívoca das perguntas, correspondência entre o universo de referência das perguntas e o universo do entrevistado, atmosfera de confiança no momento da administração do questionário, honestidade e consciência profissional dos entrevistadores. ${ }^{17}$

O inquérito por questionário utilizado organizou-se por tópicos sob a forma de itens, sendo constituído por perguntas pré-codificadas, em que a escala de resposta apresenta um formato de Likert. Portanto, constituiu-se como um instrumento adequado para coleta de dados que visa a obtenção de conhecimento científico.

\section{RESULTADOS E DISCUSSÃO}

O instrumento utilizado neste estudo foi a Escala de Idadismo adaptada por Neto. ${ }^{14}$ A escala original era composta por 29 itens que analisavam as componentes cognitiva e afetiva do idadismo. A adaptação portuguesa é composta por 25 itens. ${ }^{14}$ Para o nosso estudo, foi elaborada uma nova versão da escala: para além da dirigida aos jovens, que avalia as suas representações em relação a pessoas idosas, foi adaptada uma escala para as pessoas idosas, em que são avaliadas as suas representações em relação aos jovens. Os itens de ambas as versões são idênticos em termos de conteúdo. As opções de resposta apresentam-se numa escala de Likert de 7 pontos $(1$ - fortemente em desacordo e 7 fortemente de acordo).

O termo idadismo pode ser definido de forma breve, como o preconceito e a discriminação perante pessoas idosas ou, de uma forma mais abrangente, como o preconceito e discriminação em relação a qualquer grupo etário. Neto alerta para o fato do preconceito em relação à idade assumir uma forma abrangente e para o qual é importante definir um plano de ação, em particular em algumas sociedades, em que o contato intergeracional é menos frequente e presente no, modo como os jovens e os adultos percecionam os idosos pode variar segundo as sociedades em virtude de va- riáveis tais como: tradições, estrutura familiar, grau de contacto íntimo com os idosos e modernização. ${ }^{14}$

A escolha deste instrumento foi motivada pelas suas comprovadas qualidades psicométricas, pela sua fácil aplicabilidade nos mais diversos contextos e populações e por se adequar ao objetivo do nosso estudo. Analisar se uma intervenção que promove relações intergeracionais pode fazer diminuir o preconceito e discriminação dos participantes/intervenientes face a uma faixa etária/geração contrastante. Parte da amostra foi obtida entre os participantes do Encontro Intergeracional que ocorreu na Faculdade de Psicologia e de Ciências da Educação da Universidade do Porto, Portugal, de onde recolheram-se dados junto de 25 jovens, estudantes de um curso profissional de animação sociocultural de uma Escola Secundária e junto de 25 pessoas idosas residentes de uma instituição, ambas da região do Porto, Portugal. A outra metade da amostra foi selecionada nas mesmas instituições, tendo-se procurado controlar o fato de não terem participado em intervenções desta natureza. Deste modo, para o caso dos jovens, foi escolhida outra turma que não participou no encontro e, no caso dos/as pessoas idosos/as, um grupo que também não tivesse participado no referido encontro. O grupo de pessoas idosas foi, assim, constituído por 50 participantes com idades compreendidas entre os 70 e os 90 anos. 0 grupo de jovens foi constituído por 50 estudantes do ensino secundário com idades compreendidas entre os 15 e os 20 anos.

A amostra estudada é representativa da população teórica (amostra independente), embora seja uma amostragem não aleatória intencional e de conveniência, permitindo a garantia da representatividade do grupo propositadamente relacionado para o estudo correlacional de forma a explicar um determinado fenômeno. A partir deste estudo comparado vamos tentar aferir qual o incentivo/estímulo que este tipo de iniciativas promotoras de solidariedade intergeracional, pode determinar para o entendimento/representações dos preconceitos face à idade (escala do idadismo de Fabroni).

Assim sendo e tendo em conta os objetivos da investigação, contatou-se a direção da Estrutura Residencial, onde os idosos residiam por haver um conhecimento profissional com a instituição e com uma Escola Secundária, ambas da região do Porto. As duas instituições em causa demonstraram disponibilidade e interesse na realização do trabalho, particularmente atendendo a que, em função das motivações destes públicos, quando das interações/convivências, os corroboráveis resultados do estudo poderiam constituir material de reflexão.

A intervenção visou sobretudo questionar, desafiar e confrontar o significado e o sentido das práticas de educação intergeracional e, ao mesmo tempo, investir na sua transformação e melhoria. A avaliação do seu impacto deu-se sobretudo por meio da comparação dos estereótipos em relação à faixa etária de jovens e idosos que participaram e não participaram de um encontro intergeracional.

Este estudo busca interpretar o discurso sobre a representação do envelhecimento e as várias perspetivas, afim de refletir sobre questões relativas ao envelhecimento e ao preconceito face à idade. Numa 
fase inicial, procedemos a uma análise exploratória aos dados, de forma a analisar as qualidades psicométricas do instrumento de medida: Escala de Idadismo de Fabroni, adaptada por Neto. ${ }^{14}$ Pretendíamos, deste modo, averiguar a existência de condições para a utilização dos dados recolhidos por meio deste instrumento. Para o efeito, e mais especificamente, analisamos a consistência interna do instrumento de medida, tendo concluído que a mesma era muito boa: alfa de Cronbach de .798.

Foram observadas diferenças significativas em função da participação no encontro, no grupo dos jovens: aqueles que participaram no encontro apresentaram níveis mais baixos de idadismo $(\mathrm{M}=2,55$; $\mathrm{DP}=, 48)$, do que os que não participaram $(\mathrm{M}=2,21$; $\mathrm{DP}=, 31)$ [t $(48)=3,01 ; p=, 004]$. No entanto, não foram observadas diferenças significativas, em função da participação no encontro, no geral [t $(98)=1,30 ; p=, 20]$, nem no grupo de idosos em particular [t (48) $=-1,12 ; \mathrm{p}=, 27$ ]. No nosso entender, o reforço do diálogo intergeracional e da solidariedade possíveis na educação intergeracional, passa por relações horizontais de importância e de interação. Uma vez que os vínculos sociais constituem uma componente do objetivo de alcançar «uma sociedade para todas as idades», o que implica uma análise da sociedade numa perspetiva mais ampla e em que sobressai o papel que movimenta as relações entre as diferentes gerações. ${ }^{4}$ Deste modo, facilmente se compreenderá o decréscimo do preconceito dos jovens em relação aos idosos, mas não dos idosos em relação aos jovens, ao mesmo tempo mais ausentes no conteúdo do discurso/diálogo e menos envolvidos na discussão.

Num dos itens incluídos na escala - relativo ao suicídio ser mais trágico na outra faixa etária - o grupo (jovens e idosos) que participou no encontro apresentou níveis mais baixos de concordância ( $M=2,70$; $D P=1,15)$, por comparação com o grupo (jovens e idosos) que não participou $(\mathrm{M}=3,32$; $\mathrm{DP}=1,15)[\mathrm{T}(98)=2,70 ; \mathrm{p}=, 008]$.

Este item espelha, na nossa perspectiva, o impacto mais dramático que pode ter a desproporção entre as aspirações e as satisfações nas sociedades contemporâneas. O que está subjacente é o valor, a importância e a dignidade da vida humana dos membros pertencentes a cada uma das gerações. De uma forma geral, seria de esperar que, tanto as pessoas idosas, como os jovens dessem maior importância à perda de uma pessoa mais nova. $E$, pelo fato de esta não ter cumprido o seu papel social, e pelo culto do jovem e do produtivo e pela correlativa inexistência de um estatuto social dignificante para as pessoas idosas. Importa referir que, tal como fundamentamos teoricamente neste estudo, a educação intergeracional pode produzir impacto/impulso e estímulo neste domínio, ao questionar e enfraquecer uma organização da existência social orientada por costumes e hábitos de uma comunidade. Assim, as lógicas de competição numa comunidade não têm que permanecer em permanente destaque pelo desgaste do tecido social que o mesmo reporta. Dito de outro modo, a valorização de um outro grupo, da alteridade, no caso extremo da vida, de uma faixa etária e geração, não tem que depender da desvalorização do próprio grupo a que se pertence, mas antes do entendimento de que uns e outros desempenham papéis importantes na sociedade.

Os jovens apresentam, no global, níveis mais baixos de preconceito em relação às pessoas idosas $(M=2,38$; $\mathrm{DP}=, 44)$, quando comparados com os níveis de preconceito, em relação aos jovens apresentados pelas pessoas idosas $(M=2,65 ; D P=, 38)[T(98)=-3,36 ; p=, 001]$.

A diferença ilustrada pode resultar, no nosso entender, da percepção das pessoas idosas relativamente ao fato da sociedade/comunidade os acomodar num lugar de pouca importância e significância e, muitas vezes, de exclusão social. Com a sua passagem à reforma (aposentadoria), passam a uma vida considerada inativa, não produtiva e muitas vezes isolada. Ao longo deste estudo, fomos dando conta do lugar que a sociedade/comunidade tem para este grupo etário, o que pode promover a internalização por parte das próprias pessoas idosas da imagem da velhice e do processo de envelhecimento. Este confronto a que estão sujeitos habitualmente, mina a confiança das pessoas idosas em lidar com as interações em sociedade com outras faixas etárias: sabem que a sociedade não os vê como agentes e ativos e essa imagem tem repercussões inevitáveis na sua autoimagem e no acesso à participação cívica. Esta "armadilha cultural» facilita a confrontação das expectativas que os outros criam sobre si, não otimizando as suas competências e capacidades. Este reforço da representação que a sociedade determina para as pessoas idosas parece contribuir para uma cristalização defensiva por parte das pessoas idosas das representações que têm em relação aos jovens. Por outro lado, iniciativas como a do Ano Internacional, no âmbito do qual foi desenvolvido o encontro, podem também ter contribuído para o decréscimo do preconceito apresentado pelos jovens que constituem a amostra, independentemente de terem participado ou não no encontro.

Os resultados sugerem que intervenções que visem promover a solidariedade intergeracional, ainda que muito balizadas no tempo como foi o caso do nosso encontro, podem ser particularmente eficazes no caso dos jovens: aqueles que participaram apresentaram representações significativamente menos negativas dos idosos, um menor preconceito, por comparação com os que não participaram.

Há também que sublinhar que, no grupo das pessoas idosas, uma intervenção assim circunscrita no tempo não teve qualquer impacto significativo nos seus níveis de preconceito em relação aos jovens. Conforme o referido, para este resultado muito pode ter contribuído a mensagem geral da intervenção, que focou a solidariedade intergeracional pela via do enaltecimento de um grupo que se acredita menos privilegiado e em maior risco de exclusão - as pessoas idosas - em detrimento do outro grupo em intervenção - os jovens. Esta mesma mensagem do encontro e do Ano Internacional no geral, poderá ter também contribuído para dois dos outros resultados encontrados: a menor concordância com o fato de o suicídio ser mais dramático na outra faixa etária entre aqueles que participaram no encontro e os níveis mais elevados de idadismo, enquanto preconceito em relação a outra faixa etária (neste caso os jovens), nas pessoas idosas. Os resultados sugerem, deste modo, que este tipo de encontro pode combater algum preconceito face à idade, e em particular para as pessoas idosas. Este tipo de intervenção terá, por um lado, que ser mais alargado e sustentado no tempo 
e, por outro, mais baseado no diálogo simétrico, para contribuir para a desconstrução de estereótipos em relação aos jovens, no grupo das pessoas idosas. Como refere Jacob, ${ }^{18}$ o envelhecimento da população é um dos maiores êxitos da humanidade, porém é também um dos seus maiores desafios, devido às suas consequências sociais, económicas e politicas. ${ }^{18}$

Os desafios salientados pelo autor supracitado reconhecem, a nosso ver, a importância da solidariedade intergeracional, enquanto pressuposto de uma sociedade de e para todas as idades. É feito, neste contexto, um grande desafio à educação intergeracional e à intervenção comunitária. O envelhecimento da população e as especificidades da população idosa têm, em nosso entender, enorme interesse pelas projeções demográficas e pela necessidade de se compreender e intervir neste processo contínuo, universal e irreversível. O estudo do envelhecimento, nas suas dimensões biológica, psicológica e social, é um campo multi e interdisciplinar que visa a descrição e explicação das mudanças típicas no processo de envelhecimento e de seus determinantes genético-biológicos, psicológicos e socioculturais. ${ }^{18}$ Jacob destaca a gerontologia como o conhecimento que analisa os acontecimentos ligados à idade, ao envelhecimento e à velhice, aludindo a que $o$ envelhecimento (...) representa a dinâmica da passagem do tempo e a velhice inclui como a sociedade define as pessoas idosas. ${ }^{18}$ Muitas são as teorias associadas ao envelhecimento e ao seu processo. No entanto, estamos certos que a que mais se manifesta neste grupo populacional é a teoria da Desinserção. ${ }^{19}$ Esta teoria considera que, com o envelhecimento, vai havendo uma distância entre a pessoa idosa e a sociedade, o que leva a perda de poder e consideração no seio da comunidade. E neste sentido, deve estimular-se a sensibilização para educação intergeracional, com o intuito de uma aprendizagem integral em termos de estratégia educativa e de desenvolvimento humano e social.

É este o foco fundamental da nossa investigação que se pretende poder constituir um contributo para uma educação plural baseada numa cidadania participativa. Este estudo procurou, assim, apresentar-se como um incentivo à educação intergeracional centralizada no desenvolvimento/partilha de saberes, atitudes e competências que proporcionam a interação e solidariedade intergeracional.

Importa reiterar a inexistência de uma política global e integral para a terceira e quarta idades, onde se encontram por resolver as questões da participação e da cidadania plena e ativa como um domínio a priorizar no combate à pobreza e à exclusão social. ${ }^{20}$ Daí resultam as questões da exclusão, permanecendo como um fenômeno multidimensional, não apenas por causa das múltiplas orientações que inspira. Mas, também, pela forma como descreve a natureza multifactual da privação social nas sociedades avançadas, assim como a forma como os processos de negligência e marginalização crónicos (...) se tornam sintomas de injustiça social. ${ }^{3}$ Esta questão é fundamental quando se pensa na complexidade das relações interpessoais e intergeracionais nos dias de hoje. No entanto, cumpre-nos, enquanto cidadãos/as de pleno direito uma ação mais fiscalizadora/vigilante, para que os princípios pensados em prol desta faixa etária se realizem e não fiquem senão no papel. Ou seja, que estes princípios orientadores de e para a qualidade das políticas do Estado, se pratiquem, no desígnio de ser menos frequente a despersonalização, a desinserção familiar e comunitária, a massificação e a rotina.

A pessoa idosa, com projetos existenciais, continua ativa e integrada na sociedade, mantendo, para além da imagem biótica, a imagem relacional, auto e hetero-pessoal, e integrada numa sociedade com voz, vontade, veto, cidadania e participação. A categoria social de idosos não é homogênea nem está afastada da realidade, uma vez que cada pessoa idosa tem uma história de vida, determinada pelo seu patrimônio genético e psicossocial. O que se pretende é que a pessoa idosa seja sinônimo de uma pessoa que contribuiu e contribui para a sociedade, e que se mantém em sociedade, visível e com voz, reforçando uma atitude cívica e de forte consciência social. Almeja-se que o desenvolvimento das sociedades passe não apenas pela criação de condições para as pessoas sobreviverem e dialogarem sobre os seus problemas. Da mesma forma, para viverem de pleno direito e assumindo uma posição de empoderamento (empowerment) político quanto às suas vidas e à sua comunidade, participando ativamente na resolução e prevenção dos mesmos, com um estatuto de diferença/alteridade que não se converta em menoridade, mas antes em mais-valia por toda a sapiência conquistada pela vida experienciada.

\section{CONSIDERACÕES FINAIS}

A elaboração deste artigo possibilitou a reflexão em torno de uma Intervenção Comunitária no âmbito da Educação Intergeracional, tendo em conta os dois grupos envolvidos. Concluímos que essa reflexão poderia contribuir para o entendimento das perspectivas e das representações do envelhecimento e da juventude e para a importância/autoridade da solidariedade intergeracional. Nos pressupostos motivacionais para o encontro sobressaía há muito tempo a vontade de envolver vários grupos etários num momento de partilha em contexto universitário, para levar a cabo uma tertúlia/ roda de conversa sobre Educação Intergeracional. O intuito era promover um espaço de interação, na lógica de aprendizagem ao longo da vida e de solidariedade entre gerações e avaliar o seu impacto na desconstrução de estereótipos associados à idade.

$\mathrm{O}$ momento de riqueza e partilha que este encontro suscitou, também parcialmente refletidos nos resultados obtidos, pareceu-nos ser, efetivamente, a grande mais-valia do encontro. O seu caráter idiossincrático foi de não se ter falado das ou pelas pessoas idosas, mas com as pessoas idosas. Por outro lado, a bandeira erguida, a principal mensagem, foi do enaltecimento da pessoa idosa. Foi, assim, promovida uma maior reflexão e debate em torno do envelhecimento e das pessoas idosas, em detrimento dos jovens. Este parece ser o principal motivo por detrás do fato das pessoas idosas que participaram no encontro não terem apresentado níveis de preconceito mais baixos em relação aos jovens, do que os que não participaram no encontro, ao contrário do impacto percebido decorrente da participação 
no encontro por parte dos jovens.

A finalidade deste estudo passou por aplicar os conhecimentos adquiridos, no sentido de melhorar a performance e a intervenção em contexto educativo, adquirir competências teóricas, metodológicas e técnicas, conjugando teoria e prática. Além disso, desenvolveu-se uma atitude de intervenção socioeducativa na comunidade, para além do sentido de transformação e mudança social. Possibilitou a consideração sobre o modo como nos vemos e nos revemos na ação, verificando a existência de obstáculos que frustram os objetivos e intenções educativas. Quer nas tutorias, quer em debate interpares, foi possível ir identificando e discutindo as situações educativas de caráter intergeracional que possam promover a solidariedade entre as gerações, usufruindo da oportunidade de amadurecer e avançar no sentido pretendido, assim como ir confrontando os próprios estereótipos e preconceitos impostos pelo viés da paixão pelo envelhecimento e pelas pessoas idosas.

O objetivo foi fazer um estudo comparativo de dois grupos de jovens e pessoas idosas que participaram e não participaram no encontro, aferindo, deste modo, o impacto que este tipo de intervenção tem no preconceito face à idade, uma vez que acreditamos que a educação intergeracional no campo da intervenção comunitária se reveste da maior importância na aplicação a este domínio. A vida em comunidade na contemporaneidade está complexificada, originando representações e perspectivas díspares em diferentes gerações pela falta de interação e convivência. Os nossos resultados sugerem que a intervenção comunitária, no domínio da educação intergeracional poderá, efetivamente, contribuir para combater preconceitos e cristalizações e potenciar/promover políticas de solidariedade intergeracional. A espécie humana distingue-se pelo fato de se estabelecer no seio de relações sociais, transversalmente, numa gama de conexões e interações, enquadrada numa construção coletiva enraizada culturalmente. A cultura aparece, então, como quadro de referência, como provedora de um conjunto de recursos, de oportunidades, mas também de constrangimentos para as mais variadas condições pessoais, sociais, psicológicas. Estes recursos, oportunidades e constrangimentos são característicos de um dado momento espaço-temporal, de um determinado contexto, onde se partilham valores, ações e recursos de uma comunidade.

As situações constrangedoras a que a pessoa idosa e os jovens estão sujeitos, na sociedade contemporânea, são tanto mais agravantes, quanto maior for a falta de solidariedade intergeracional suscitada pelo individualismo e pelas vidas estressantes a que nos habituamos. Importa debater sobre quem é o protagonista da vida de cada um e qual o papel das comunidades, das famílias e das pessoas na sociedade atual. São determinantes do envelhecimento ativo, identificado na II Assembleia Mundial das Nações Unidas, os fatores sociais, pessoais, de saúde e serviços sociais, meio físico, económicos, e comportamentais. Estes são os requisitos para o alcance duma abordagem holística e integrada na sua concepção e, por conseguinte, na consolidação de uma sociedade mais humanizada, baseada em princípios de solidariedade intergeracional.

Portanto, o profissional, seja do campo social, da educação ou da saúde, poderá e deverá, assim, ter um papel interventivo fundamental neste domínio. Para tal, é importante que tenha consciência da perspectiva dominante das culturas em que está integrado para que possa refletir acerca das mesmas e das respectivas implicações e possa assim estar disponível para conhecer outras perspectivas. Pois, enquanto profissional da relação, têm de ter a capacidade de uma multiplicidade de olhares face à realidade tendo em conta as especificidades dos intervenientes. Fomenta-se, assim, a possibilidade de refletir sobre conceitos que estão presentes no dia a dia sob outras perspectivas, que nunca havíamos ponderado de um ponto de vista educativo, sociológico ou das ciências biológicas, sociais e humanas, o que se comprovou ser uma provocação ainda mais desafiante. Emerge, assim, a importância e a contribuição deste estudo para o crescimento acadêmico, profissional e pessoal.

Este manuscrito divulga a impressionabilidade dos sentidos e interpretação que tentamos dar à solidariedade intergeracional: perspectivas e representações. O próprio título do nosso estudo, Envelhecimento: perspectivas, representações e solidariedade intergeracional, espelha a intencionalidade de um estudo comparativo entre jovens e pessoas idosas, relativamente às suas perspectivas e representações sobre o envelhecimento. De algum modo espelha o enviesamento que pode ter estado subjacente a este estudo comparativo, concedendo o enaltecimento das pessoas idosas, proporcionalmente aos jovens. O que se pretendia era comparar os preconceitos recíprocos entre estas duas faixas etárias, sendo entendidas ambas as direções de preconceito como barreiras a uma efetiva solidariedade intergeracional.

É importante realçar que, apesar das dificuldades verificadas, há que valorizar a oportunidade de permanecer e agir com autonomia, durante todo o processo de investigação, assim como desenvolver lógicas e práticas de exercício. O questionar de modos de atuação em Educação Intergeracional, da e na Intervenção Comunitária, com o objetivo de promover a solidariedade e a educação intergeracional permitiu adquirir-se competências teóricas, metodológicas, técnicas e humanas de forma a questionar as práticas, tendo a oportunidade de conhecer as representações sociais das pessoas idosas e dos jovens. Nesse sentido, valorizamos o enfoque nas potencialidades que, em conjunto, desenvolvemos e consolidamos em termos educativos, na interpelação com estas pessoas.

O percurso de estudo permitiu o desenvolvimento de uma reflexão e de uma intervenção que se pretende mais consciente das suas próprias limitações mas também das potencialidades, ainda não exploradas em termos educativos nestes contextos. Este modo de percepcionar esta realidade profissional e institucional, pretende de algum modo alcançar a transformação social, numa sociedade que se deseja mais interveniente, humana e solidária.

Tendo em conta a multirreferencialidade das $\mathrm{Ci}$ ências de Educação que aproxima o sujeito e o objeto, proximidade que a epistemologia de escuta aponta no sentido da emancipação - grande impulsionadora da procura de sentido e de significado para as escolhas dos participantes deste estudo, ao tentar conhecer um 
determinado lugar (contexto), a partir dos olhos dos outros, estamos a dar-Ihes oportunidade de se implicarem no processo de conhecimento e tornarem-se, também, agentes do seu próprio desenvolvimento, contribuindo para que se constitua uma cidadania cada vez mais plena.

Neste estudo, muito ficou por desenvolver e conhecer no âmbito da solidariedade e no que respeita aos grupos de pessoas idosas e de jovens, e muito poderá fazer-se no futuro, embora se saliente a finalidade da ação no âmbito do Ano Europeu do Envelhecimento Ativo e Solidariedade entre Gerações (AEEASE). Identificou-se uma possibilidade de ampliação deste campo de estudo, como uma oportunidade de investigação e intervenção educativas, muito pertinente e pouco explorada. Para além das modificações na intervenção, seria interessante também em estudos futuros avaliar o impacto da mesma noutras variáveis para além do preconceito, como é o caso das práticas de solidariedade intergeracional, no contexto familiar e social.

A avaliação deste impacto ganharia também mais sustentabilidade com um desenho experimental, com coleta de dados antes, imediatamente após e passados seis meses da intervenção. Deste modo, poderia ser possível averiguar a manutenção dos possíveis ganhos de uma intervenção comunitária.

Ainda neste sentido, um trabalho neste sentido no Brasil também pode ser muito bem vindo para se compreender melhor as relações quanto às políticas públicas sobre as intergeracionais presentes no país.

\section{REFERÊNCIAS}

1. Cabral M. Envelhecimento: Perspetivas e Representações e Solidariedade Intergeracional [Ageing: Perspectives, Representations and Intergenerational Solidarity]. Master Dissertation. Faculty of Psychology and Educational Sciences, Porto University, 2013.

2. Bauman Z. A sociedade individualizada: vidas contadas e histórias vividas. Rio de Janeiro: J. Zahar, 2009.

3. Stoer SR, Magalhães AM. O Lugar da Cidadania. In Stoer SR; Magalhães AM. A Diferença Somos Nós - A gestão da mudança social e as políticas educativas e sociais (pp. 62 101). Porto: Edições Afrontamento, 2005.

4. Relatório do Desenvolvimento Humano. Sustentar o Progresso Humano: Reduzir as Vulnerabilidades e Reforçar a Resiliência Publicado pelo Programa das Nações Unidas para o Desenvolvimento (PNUD), Camões, Instituto da Cooperação e da Língua, Portugal, Ministério dos Negócios Estrangeiros, 2014.

5. Oliveira D. O problema não é o despesismo do Estado. Expresso, 02/03, 2012. http://expresso.sapo.pt/blogues/ opiniao_daniel_oliveira _antes_pelo_contrario/oproblema-nao-e-o-despesismo-do-estado $=\mathrm{f} 708413$

6. Bengtson VL, Roberts REL. Intergenerational solidarity in aging families: An example of formal theory construction. Journal of Marriage and the Family 1991;53(4):856-70.

7. Steinbach Anja. Intergenerational Solidarity and Ambivalence: Types of Relationships in German Families. Department of Sociology, School of Humanities and Social Sciences, Chemnitz University of Technology, Reichenhainer Str 2005;41:115-27.

8. Coimbra S, Ribeiro LA, Fontaine AM. Intergenerational Relations European Perspetives on Family and Society. Intergenerational Solidarity in an ageing world: Sociodemographic determinants of intergenerational support to elderly parents, 2013;205-22.

9. Palmeirão CMGC. A interação geracional como estratégia educativa: um contributo para o desenvolvimento de atitudes, saberes e competências entre gerações. Tese de Doutoramento apresentada à FPCE-UP, 2007.

10. Perrwnoud P. Escola e Cidadania - O Papel da Escola na Formação para Democracia. Porto Alegre: Artmed, 2005.

11. Marshall TH. Cidadania, Classe social e Status. Rio de Janeiro: Zahar Editores, 1967.

12. Karsz Saul. Déconstruire la Vieillesse. Les Cahiers de la Recherche sur le Travail Social, 15, 1998.

13. Giddens Anthony. Modernidade e identidade pessoal. Oeiras: Celta Editora.1994.

14. Neto F. Idadismo. In Lima ME, Pereira ME. (Org.) Estereótipos, preconceitos e discriminação - perspetivas teóricas e metodológicas. 279-31, 2004.

15. Neves Tiago. Mediação Comunitária e Mudança Social. Cadernos de Pedagogia Social, 45-60, 2009.

16. Bourdieu P. A Miséria do Mundo. Metrópolis: Vozes Editora, 1997.

17. Quivy R; Campenhoudt LV. Manual de Investigação em Ciências Sociais (5 Edição ed.). Lisboa: Gradiva, 2008.

18. Jacob Luis. Animação de Idosos. Coleção Geriatria e Gerontologia. Porto: Mais Leitura Editora, 2013.

19. Cumming E, Henry WE. Growing old, Nueva York, Basic Books, 1961.

20. Neves TC, Isabel SMR. Ação Local no Combate à Pobreza e Exclusão Social. Porto: Livpsic, 2010.

Como citar: CABRAL, Maria da Luz Leite; MACUCH, Regiane da Silva. Solidariedade intergeracional: perspectivas e representações. Cinergis, Santa Cruz do Sul, v. 18, n. 1, out. 2016. ISSN 2177-4005. Disponível em: <https://online.unisc.br/seer/ index.php/cinergis/article/view/8393>. Acesso em: 11 out. 2016. doi:http://dx.doi.org/10.17058/cinergis.v18i1.8393. 